\title{
ESTRATÉGIAS DE CUSTOMIZAÇÃO EM MASSA: UM ESTUDO DE CASO NA INDÚSTRIA DE FABRICAÇÃO DE MÓVEIS MODULARES
}

\section{MASS CUSTOMIZATION STRATEGIES: A CASE STUDY OF THE MODULATED FURNITURE INDUSTRY}

\author{
André Gustavo Carvalho Machado ${ }^{1}$; Walter Fernando Araújo de Moraes $^{2}$ \\ ${ }^{1}$ Universidade Federal da Paraíba - UFPB - João Pessoa - Brasil \\ agcmachado@gmail.com \\ ${ }^{2}$ Universidade Federal de Pernambuco - UFPE - Recife - Brasil \\ wfam@br.inter.net
}

\begin{abstract}
RESUMO
O objetivo deste artigo foi analisar as estratégias de customização em massa adotadas por uma empresa líder do segmento de fabricação de móveis modulares .A estratégia de pesquisa selecionada foi de estudo de caso único. Para obtenção dos dados necessários foram realizadas entrevistas semi-estruturadas. A análise dos dados foi realizada em cinco fases. Os resultados permitiram concluir que foram adotadas estratégias alicerçadas na utilização de módulos $e$ postergação da fabricação e da montagem. Identificou-se a existência de dois pontos distintos de desacoplamento do pedido do cliente. Seis habilitadores foram considerados essenciais para a customização em massa: manufatura baseada no tempo, cadeia de suprimento, flexibilidade do sistema de produção, projeto do produto, produção enxuta e tecnologia de informação.
\end{abstract}

Palavras-chave: Customização em massa, estratégia, estudo de caso, modularização, postergação.

\section{Introdução}

Customização em massa diz respeito à "habilidade de fabricar, rapidamente, uma diversidade de produtos customizados, em grande escala, e a custos comparáveis à produção em massa" (TU et al, 2004, p.152). Estratégia de customização em massa, por sua vez, pode ser entendida como o conjunto de planos que irá servir de referência para a tomada de decisões (associadas à alocação de recursos e implementação de ações), no sentido de satisfazer às necessidades individuais dos clientes, por meio da rápida disponibilização de bens e serviços, a custos baixos e em grande escala. 
Embora a customização em massa já tenha se mostrado possível para uma série de produtos, tais como: bicicletas (KOTHA, 1996), calçados, calças jeans, livros infantis, computadores, armações para óculos (PEPPERS e ROGERS, 1997), roupas esportivas (LEE e CHEN, 2000), cereais e misturas para chá (PILLER, 2007), não foram evidenciadas, na literatura pesquisada, discussões aprofundadas sobre o uso desta estratégia no setor de fabricação de móveis, ainda que o advento de móveis modulares tenha sido introduzido há muitas décadas atrás.

No que tange a estudos sobre estratégias de customização em massa no Brasil, a revisão da literatura permitiu concluir que, apesar dos recentes artigos publicados sobre o tema (MACHADO e MORAES, 2008a, 2008b, 2009), ainda há carência de estudos, no âmbito nacional, sobre como estas estratégias estão sendo executadas, indicando que mais pesquisas devam ser empreendidas no sentido de melhor conhecer como este fenômeno está sendo tratado pelas empresas brasileiras.

Neste contexto, este artigo tem como objetivo central analisar as estratégias de customização em massa adotadas por uma empresa pertencente ao setor de fabricação de móveis modulares. Especificamente, buscou-se diagnosticar o processo produtivo e as implicações da adoção de estratégias de customização em massa para o gerenciamento das operações, bem como identificar os habilitadores da customização em massa adotados pela empresa pesquisada.

A empresa analisada é especializada na produção de móveis modulares residenciais, estando no mercado há 69 anos. Voltada, principalmente, para o mercado interno, é líder no segmento em que atua. Suas instalações correspondem a um moderno parque fabril de $54.000 \mathrm{~m}^{2}$, o que a eleva a uma das maiores e mais avançadas fábricas de móveis da América Latina. Possui, aproximadamente, 445 funcionários e apresenta uma produção de 25.000 volumes/dia.

A empresa foi pioneira na América Latina a introduzir, em 1968, o conceito de móveis modulares para cozinhas. Até 1993 os produtos estavam concentrados em cozinhas, matérias de aço inox e balcões de banheiros. Com a abertura do mercado, na década de 90, e a partir da constatação de que havia uma demanda ávida por produtos modulares, diante de espaços residenciais cada vez menores que exigiriam planejamento prévio, a produção foi estendida para móveis modulares para toda a casa. Desta forma, pode-se afirmar que, em termos gerais, o principal aspecto motivador foi o mercadológico.

O artigo está estruturado da seguinte maneira: inicialmente será realizada uma breve fundamentação teórica, contemplando as alternativas estratégicas para a implementação da customização em massa. Em seguida, são apresentados os procedimentos metodológicos adotados. Resultados relacionados ao processo de customização, estágios onde ocorrem a customização, estratégias e habilitadores da customização em massa são discutidos à luz do referencial adotado. Por fim, são apresentadas as conclusões. 


\section{Fundamentação teórica}

Com o objetivo de propor caminhos alternativos que uma empresa possa seguir para atingir a customização em massa, Pine (1994) identificou cinco estratégias básicas, não mutuamente exclusivas, que são: 1- customizar serviços em torno de produtos e serviços padronizados; 2- criar produtos e serviços customizáveis; 3- prover pontos de entrega de customização; 4- fornecer respostas rápidas por toda a cadeia de valor; e 5- modularizar componentes para customizar produtos finais e serviços.

Analisando a extensão pela qual uma empresa pode customizar o produto ao longo de quatro outros estágios da cadeia de valor (projeto, fabricação, montagem e distribuição), Lampel e Mintzberg (1996) definiram um continuum de cinco diferentes níveis de estratégia, quais sejam: 1padronização pura; 2- padronização segmentada; 3- padronização customizada; 4- customização sob medida; e 5- customização pura.

Duray e outros (2000), por sua vez, classificaram a customização em massa em termos de duas características: o ponto no qual há o envolvimento do cliente e o tipo de modularidade empregada para prover produtos customizados. A justaposição das duas características origina quatro categorias (ou grupos) de customização em massa: fabricantes, envolvidos, modularizadores e montadores.

A partir da análise dos trabalhos de certos autores, Silveira, Borestein e Fogliatto (2001) desenvolveram uma classificação genérica envolvendo oito diferentes níveis de customização em massa: projeto; fabricação; montagem; trabalho customizado adicional; serviço adicional; embalagem e distribuição; utilização; e, por fim, padronização.

Ademais, a localização de diferentes pontos a partir do qual será executada a customização está associada ao conceito de postergação (postponement), isto é, o retardamento de certas atividades de diferenciação do produto ou do serviço até o recebimento do pedido do cliente (VAN HOEK, 2001). Nesta perspectiva, diferentes níveis de postergação podem ocorrer de acordo com o local na cadeia de suprimentos em que o produto é customizado, tais como postergação da manufatura e da logística ou distribuição.

O objetivo da postergação da manufatura é manter o produto em estado neutro até o último momento possível no processo de adição de valor. Isto permite que sejam executados diferentes tipos de postergação: fabricação, montagem, embalagem e etiquetagem (ZINN, 1990).

A postergação da logística ou distribuição, por seu turno, consiste em manter produtos acabados estocados em apenas um ou alguns locais estratégicos, onde os produtos são deslocados a partir do pedido do cliente. Apesar deste tipo de customização não influir na customização do produto, é por meio dele que se obtém redução dos níveis dos estoques ao longo da cadeia de 
suprimentos (WALLER, DABHOLKAR, GENTRY, 2000; YANG, BURNS, BACKHOUSE, 2004), e diminuição do tempo compreendido entre o pedido e a entrega dos produtos para os clientes (BOWERSOX e CLOSS, 2001).

Por outro lado, caso a empresa realize tanto as atividades de manufatura quanto de logística ou distribuição contra-pedidos dos clientes, significa que ela executa a estratégia de postergação plena, a qual representa o mais alto nível de aplicação da postergação (PAGH e COOPER, 1998).

Assim, a postergação de tarefas ao longo da cadeia de suprimentos constitui uma das estratégias passíveis de serem adotadas para o alcance dos objetivos da customização em massa (VAN HOEK; 2001; CARMO e GAVRONSKI, 2002; BERMAN, 2002; HERMANSKY e SEELMANN-EGGEBERT, 2003; YANG, BURNS, BACKHOUSE, 2004).

No contexto brasileiro, resultados de uma ampla pesquisa utilizando estudos de casos múltiplos revelaram que o alcance dos objetivos da customização em massa é decorrente da utilização conjunta de estratégias alicerçadas em modularização e postergação (MACHADO e MORAES, 2008b).

\section{Procedimentos metodológicos}

A estratégia de pesquisa selecionada foi a de estudo de casos único (YIN, 2001). Os critérios de seleção da empresa dizem respeito ao fato de que a mesma foi uma das primeiras na América Latina a introduzir o conceito de móveis modulares para cozinhas, além de ser líder do país no seu segmento. Para obtenção dos dados necessários, além de observações diretas, foram realizadas entrevistas semi-estruturadas com o Gerente Industrial, Analista Técnico do Setor Produtivo e a responsável pela área de Desenvolvimento de Produto. O número de entrevistados decorreu da disponibilidade de acesso.

Para execução das entrevistas, foi elaborado um roteiro de tópicos relativos ao problema em enfoque, contendo vinte e cinco questões abertas divididas em dois blocos. No primeiro bloco, as questões buscaram investigar, de forma ampla, a motivação, os critérios para seleção dos componentes a serem customizados, as características do processo e a extensão da customização, bem como o relacionamento entre as atividades. As demais questões, pertencentes ao segundo bloco, tiveram o intuito de diagnosticar as práticas, métodos e ferramentas que poderiam habilitar a empresa a executar a customização em massa.

Concluídos os procedimentos de planejamento da pesquisa, foram realizados, inicialmente, contatos telefônicos e por e-mail com representantes da empresa-alvo da investigação. Em seguida, as questões centrais envolvidas no roteiro de entrevista, juntamente com uma carta de apresentação, foram enviadas aos respondentes da pesquisa. 
Ao final de cada entrevista, foi solicitado que cada entrevistado respondesse a um pequeno questionário que contemplava informações básicas sobre a empresa e sua atividade como profissional. Além das entrevistas, também foi possível visitar a área fabril da empresa, permitindo uma melhor compreensão das ações implementadas.

A análise dos dados foi realizada em cinco fases, tomando como referência a técnica de procedimento analítico geral (COLLIS; HUSSEY, 2005) e as considerações empreendidas por Merriam (1998) e Eisenhardt (1989). Desta forma, a primeira fase pode ser compreendida como uma pré-análise na qual, concomitantemente à observação in loco e à transcrição das gravações das entrevistas, os pesquisadores adicionavam suas impressões e reflexões. Em seguida, numa segunda fase, foram realizados esforços no sentido de identificar a possibilidade de agrupar os dados em categorias. Neste sentido, emergiram três categorias primárias de análise: processo de customização em massa, estratégias de customização, habilitadores da customização em massa.

Numa terceira fase, foi elaborado um relatório contendo uma explanação a respeito das categorias obtidas na fase anterior. O relatório foi enviado (por e-mail) para os entrevistados da empresa pesquisada. Por meio de uma carta anexada ao relatório, foi solicitada que se fizesse uma avaliação a respeito da análise dos dados desenvolvida, com o objetivo de verificar a conformidade dos resultados à realidade observada. Pretendeu-se, por meio deste procedimento, contribuir para o alcance da validade interna dos dados.

De posse dos comentários dos entrevistados, os pesquisadores, numa quarta fase, revisaram a análise previamente realizada, de modo a torná-la o mais realista possível. Os resultados, na quinta e última fase, foram analisados à luz da teoria que fundamenta o assunto em enfoque.

\section{Apresentação dos resultados}

A seguir, são apresentados e discutidos os achados da pesquisa, destacando as principais categorias que emergiam dos dados coletados: processo de customização, estratégias de customização em massa e habilitadores da customização em massa.

\subsection{O processo de customização em massa}

Uma vez que há a participação efetiva do consumidor final nas características do produto que será disponibilizado, as atividades de customização iniciam nas lojas exclusivas da empresa. Assim, normalmente, o arquiteto do consumidor final, em conjunto com o projetista da loja, elabora o projeto do móvel, seguindo os requisitos especificados pela fábrica. Para apoiar esta tarefa é 
utilizado um software (Promob) que, automaticamente, lista todos os módulos, peças e acessórios gerando assim o pedido para o Representante de Vendas.

O Representante, por sua vez, analisa o pedido e verifica a existência situações especiais (aquelas que não estão no catálogo) e envia para a fábrica. Para as situações especiais, a área de produção verifica a possibilidade de fabricação de peças customizadas especiais. Desde que não sejam exigidos procedimentos que fujam bastante da rotina da produção, o produto pode vir a ser especialmente customizado. Estes casos, contudo, constituem exceções.

Normalmente, os pedidos são atendidos por meio da combinação de peças padronizadas e catalogadas. Estes casos são caracterizados pela fabricação de componentes modulares, no início do processo produtivo, para alimentar o almoxarifado. Estas peças são intercambiáveis e servirão para compor as diversas opções de construção de produtos finais que atendam às exigências individuais dos clientes. Logo, devido à estratégia de modulação de componentes, não há estoque de produto acabado.

As peças padronizadas são produzidas de acordo com seu nível de consumo. As peças que possuem uma maior freqüência de saída, por exemplo, são repostas a cada três ou quatro dias. As peças de menor giro são observadas separadamente para tomada de decisão referente à reposição. Estas peças possuem estoque de 15 a 90 dias.

Quando há o pedido do mercado, inicialmente são consumidas as peças estocadas. Na medida em que se atinge o nível de segurança, a produção é programada para repor os itens consumidos. Para isto, trabalha-se sob a lógica de família de peças. As peças apenas são fabricadas quando há a necessidade de repor os itens consumidos nos estoques pertencentes às respectivas famílias programadas para o dia. Ou seja: mesmo que tenha alcançado o estoque de segurança, uma peça apenas será fabricada se for o dia programado para sua respectiva família.

Existem 4.000 itens apenas fabricados pela empresa, sem levar em consideração aqueles entregues pelos fornecedores, como é o caso vidros ou portas de alumínio. Desta forma, tem-se um estoque de produtos intermediários, peças prontas antes da embalagem, pois só assim seria possível otimizar a entrega de produtos finais. De maneira diferente, seria necessário realizar mais de 600 setups por dia para atender às diferentes necessidades do mercado.

Desta forma, quando é planejada a fabricação de produtos, observa-se inicialmente o número de peças polivalentes que já existem no almoxarifado, a fimm de não elevar o estoque. Estas tarefas são auxiliadas por um sistema informatizado, o qual, virtualmente, dá baixa automática no estoque de peças necessárias para o atendimento de cada pedido futuro, possibilitando identificar a quantidade e a variedade de peças remanescentes no nível de estoque no almoxarifado. 
Além disto, existem as peças (tampos e prateleiras lineares) que são fabricadas (cortadas) de maneira diferenciada para cada cliente, isto é, de acordo com especificações individuais, as quais apenas entram no processo dois dias antes da data de embalagem e expedição.

Como o projeto é modular, quando se tem uma parede na casa do consumidor final de "n" metros de comprimento, o projetista da loja onde foi realizado o pedido, em conjunto com o arquiteto do cliente, irá preenchê-la com módulos de diferentes dimensões. Por cima de todos os módulos é fixado um único tampo, que é uma peça inteira.

Contudo, é possível que o somatório da combinação de módulos não seja suficiente para ocupar todo o espaço necessário. Como o tampo deve preencher todo o espaço da parede destinada ao móvel, e como cada caso é um caso, não é viável produzir os tampos previamente, pois se assim o fosse, ter-se-ia que estocar tampos de diferentes dimensões e cores.

Por outro lado, caso houvesse um tampo para cada módulo, haveria uma série de emendas na montagem dos módulos, o que não resultaria em um bom acabamento. Assim, tem-se que fabricar o tampo sob medida em termos do comprimento, já que a largura e a profundidade são padrões. Ele não é uma peça padronizada como os módulos. Os tampos são cortados just in time. Assim, o grande volume de peças padronizadas se soma às peças customizadas resultantes da fabricação de tampos e prateleiras lineares.

Concluída a fabricação do pedido, a fábrica envia, por meio de empresa transportadora, o pedido para o lojista, o qual realiza uma pré-montagem no próprio estabelecimento e a montagem final na residência do cliente.

Desta forma, existem dois pontos onde ocorrem a customização dos produtos: fabricação de tampos e prateleiras lineares; e montagem de peças modulares. No primeiro caso, as peças são fabricadas de acordo com as dimensões exigidas pelos clientes, necessitando para isto, de atividades de corte diferenciadas. O segundo caso diz respeito à montagem por meio da combinação de módulos padronizados, os quais são intercambiáveis entre os diferentes modelos oferecidos no mercado.

Enquanto a fabricação de peças ocorre exclusivamente na área fabril, a montagem do produto final acontece na residência do cliente e é realizada por funcionários da rede de lojas localizadas nas diferentes regiões do país. Atualmente, a empresa apenas trabalha com lojas exclusivas.

Neste sentido, os lojistas estão sendo incentivados a montar mini-marcenarias a fim de realizar pequenos ajustes nas peças para atender às exigências dos consumidores durante a montagem. É o caso, por exemplo, do "fechamento", no qual há a necessidade de cortar um painel para preencher um espaço não ocupado por módulos. 
Esta adequação do produto mais próximo do consumidor final faz com que haja maior rapidez no atendimento dos pedidos. Significa que se está postergando a montagem para o ponto mais próximo do cliente. Desta forma, o papel do lojista é fundamental para o processo de customização.

\subsection{Estratégias de customização em massa}

Ao se analisar as características operacionais do processo de customização da empresa, sob a perspectiva das abordagens desenvolvidas por diversos autores (quadro 1), conclui-se que foram adotadas, essencialmente, duas estratégias para implementar a customização em massa: modularidade e postergação da manufatura.

Os principais tipos de modularidade adotados dizem respeito à modularidade por ajuste de componentes e modularidade seccional (DURAY e outros, 2000). O primeiro caso lida com a necessidade de ajustar as dimensões (em termos do comprimento) dos componentes para atender às especificações dos clientes. O segundo caso envolve a possibilidade de combinar diferentes peças (que compõem modelos diversos) por meio de encaixes e conexões padrões.

Quadro 1 - Abordagens de customização em massa na empresa pesquisada

\begin{tabular}{|c|c|}
\hline Autores & Abordagens de Customização em Massa \\
\hline Zinn (1990) & Postergação da fabricação e da montagem \\
\hline Pine (1994) & Produção modular \\
\hline Lampel e Mintzberg (1996) & Customização sob medida \\
\hline Duray et al (2000) & Modularizador \\
\hline Silveira, Borestein e Fogliatto (2001) & Fabricação e Montagem \\
\hline
\end{tabular}

Fonte: Elaboração Própria

No que diz respeito à estratégia de postergação da manufatura, um importante requisito para o alcance deste objetivo consiste na possibilidade de dividir o processo produtivo em, pelo menos, dois estágios: primário e secundário (VAN HOEK, COMMANDEUR, VOS, 1998). O estágio primário seria responsável pela produção de componentes padronizados, focando, pois, os benefícios da economia de escala. O estágio secundário, por sua vez, seria responsável pelas tarefas de diferenciação do produto para atender às necessidades individuais de cada cliente. $\mathrm{O}$ ponto no qual há a divisão entre a produção padronizada da customizada é denominado ponto de desacoplamento do pedido do cliente (customer order decoupling point) (VAN HOEK, 2001).

O ponto de desacoplamento entre a fabricação em massa e a customizada na empresa analisada ocorre no momento em que as peças dos tampos e das prateleiras lineares assumem 
comprimentos específicos de acordo com as necessidades individuais dos consumidores finais. Isto acontece após estas mesmas peças passarem pelas etapas padronizadas do processo de fabricação, onde são definidas as larguras e profundidade padrões. O segundo ponto de desacoplamento, por sua vez, ocorre no momento da montagem e do ajuste das peças padronizadas na residência do cliente.

A utilização das estratégias supracitadas garante o desempenho eficiente do processo de customização em massa, tornando possível disponibilizar milhares de volumes por dia, trabalhando apenas um turno.

\subsection{Habilitadores da customização em massa}

A partir da análise dos dados, foi possível identificar os principais fatores por meio dos quais a empresa conseguiu implementar seus objetivos, entendidos nesta pesquisa como habilitadores da customização em massa, conforme discriminado a seguir.

\subsubsection{Tecnologia de informação e flexibilidade do sistema de produção}

Para aumentar a flexibilidade e a velocidade, reduzir custos unitários e problemas associados à falhas da qualidade do produto, tanto o processo produtivo quanto o transporte de materiais é automatizado. Como conseqüência da automação, poucos empregados são necessários na operação.

Sob a perspectiva da fabricação de materiais não lineares (peças de canto, curvas, peças que exigem um trabalho manual, com maior valor agregado), a adoção do processo automatizado e integrado mediante sistemas de informação, permite que se obtenha a flexibilidade necessária para atender a diferentes pedidos dos clientes. A este respeito, 10\% dos equipamentos são flexíveis, corroborando para o atendimento a diferentes especificidades ocorra no menor tempo possível. É um número ainda pequeno, mas há previsões de maiores investimentos para a fábrica flexível. Os principais tipos de flexibilidade demandados dizem respeito à máquina, mão de obra, modificação do produto, mix e volume.

Independente da cor ou do tamanho que o mercado exige, o Planejamento e Controle da Produção (PCP) faz uma programação de modo a otimizar o processo e a velocidade das células de produção. Para dar o suporte às operações de manufatura, além de permitir a integração entre as demais áreas da empresa, investiu-se na aquisição de um software de gestão empresarial (EMS, da empresa brasileira Datasul), o qual, por meio do módulo de manufatura, provê o suporte para o planejamento e controle de materiais. A importância da adoção de sistemas de informação é 
corroborada por vários estudiosos sobre o tema da customização em massa (LAU, 1995; SILVEIRA, BORENSTEIN, FOGLIATTO, 2001).

Para lidar com o elevado nível tecnológico empregado e as diferentes exigências dos clientes, promovem-se uma intensa qualificação dos empregados, como destaca o Gerente Industrial:

[...] não conseguiríamos alcançar nossos resultados em termos de flexibilidade sem pessoas qualificadas. Nós queremos as pessoas as mais polivalentes possíveis. Treinamos para que as pessoas possam operar diferentes máquinas numa mesma célula. Afinal, as pessoas podem ficar doentes. Quem entra na fábrica começa com funções mais simples e vai se desenvolvendo ao longo do tempo. O ser humano é o diferencial.

As ações citadas e executadas pela empresa estão em consonância com o apregoado por Slack (1993), o qual destaca como condição para implementação do conceito de flexibilidade nos sistemas produtivos a necessidade de que haja investimentos não só em automação, mas também em capacitação de pessoal.

Ademais, no que diz respeito à formação de pessoas polivalentes, Tubino (1999) chama a atenção que a flexibilidade dos sistemas produtivos tem por base a distribuição de trabalhos entre operadores polivalentes ou multifuncionais, os quais têm como função absorver as variações da demanda pela mudança de sua rotina de operações padrão. Além disto, a multifuncionalidade permite a execução simultânea de operações secundárias ou selecionadas e a operação principal, utilizando-se os tempos de folga existentes, agregando flexibilidade ao sistema (GHINATO, 1999).

Acompanhamento e controle também são fundamentais. Cada engenheiro é responsável por uma parte específica do processo, o que inclui, por exemplo, reduzir setups. O empreendimento de esforços no sentido da diminuição dos tempos de preparação de máquinas e equipamentos (setups), como asseveram Ohno (1997) e Shingo (1996), é fundamental para aumentar a flexibilidade do sistema produtivo.

Há, por sua vez, aproximadamente, 40 a 50 indicadores de desempenho. Estes são gerenciados mensalmente pelos integrantes do Grupo de Informação e Ação Gerencial. Cada indicador de desempenho possui um padrinho. Cada vez que um indicador sinaliza perda de desempenho, seu respectivo padrinho se manifesta apresentando as ações que estão sendo tomadas para ele voltar ao patamar adequado. Depois, cada supervisor passa informações para os grupos operacionais. Estas informações também estão disponibilizadas na intranet da empresa, além dos murais. 


\subsubsection{Projeto do produto}

Em relação à criação de novos produtos, existem três critérios básicos envolvidos no projeto: funcionalidade; praticidade; e design. As pessoas, atualmente, têm mais acesso à informação e estão mais exigentes em termos de estética. Por outro lado, elas não se contentam apenas com a beleza. Assim, o produto tem que provar ser funcional e apresentar facilidade para limpeza e manutenção, por exemplo.

A participação de pessoas de diferentes áreas funcionais é também importante para o processo de desenvolvimento de novos produtos, por meio de sugestões sobre projetos, não só na estética, mas na funcionalidade e na fabricabilidade. A este respeito, a profissional responsável pelo desenvolvimento de produtos comenta:

\footnotetext{
Às vezes, projetos antigos de produtos são questionados pelas equipes de produção sobre a possibilidade de modificar certos requisitos. Então eu penso: por que não? Eu não posso achar que só existe uma maneira de fabricar porque sempre foi assim. Tenho que abrir minha cabeça também, não posso ser saudosista. O mesmo acontece com nossos fornecedores. Sempre se fez cadeira com solda. Agora queremos que ele nos forneça apenas com parafusos. O fornecedor sofreu, mas conseguiu fazer exatamente o quem nós pedimos. Se nós mudamos, eles também têm que mudar, de crescer.
}

Antes de lançar uma nova linha de produtos, por sua vez, buscam-se informações de algumas fontes. Inicialmente procura-se compreender as necessidades dos lojistas. Como cada lojista possui uma exigência diferente, de acordo com a região do país, esforça-se para identificar os pontos em comum entre eles. Estes pontos são chaves, pois não seria viável atender a todos os requisitos sugeridos.

Com o objetivo de obter informações sobre os projetos elaborados em nível de loja e conhecer melhor as preferências do consumidor final, no período em que foi realizada esta pesquisa, estava em fase de finalização a implantação de um software que permitirá a integração entre a fábrica, as lojas e o consumidor final.

Outra fonte é a concorrência. Neste caso, são visitadas várias lojas dos concorrentes na busca de perceber o que a maioria deles tem que a empresa não oferece. Tendências do mercado também são analisadas. Periodicamente, são visitadas as principais feiras internacionais, como Milão e Colônia. Por fim, busca-se compreender como é possível inovar internamente.

Definido o produto, busca-se desenvolvê-lo respeitando certos parâmetros já existentes nas linhas de produção da empresa, por exemplo, a modulação, como destaca a profisssional responsável pelo desenvolvimento de produtos: 
[...] nós nunca alteramos a modulação, procuramos nos adaptar à modulação existente. Nós jamais iríamos criar uma medida fora dos padrões em vigor. Caso nós não respeitemos a modulação existente, projetando produtos com muitas variações de medidas, nós quebramos a fábrica, pois a modulação é feita em cima de um plano de corte.O que pode acontecer, em situações muito especiais, envolve criarmos uma nova modulação. Foi o que aconteceu com as medidas dos gavetões. Até dois anos atrás, praticamente não existiam gavetões de um metro. Hoje eles se transformaram em uma necessidade de mercado.

A adoção de módulos para os propósitos da customização em massa está em conformidade com as proposições de Pine (1994), Feitzinger e Lee (1997), e Dornier e outros. (2000).

Outro ponto diz respeito à otimização da utilização das máquinas e equipamentos. Caso haja uma máquina na produção que esteja subutilizada, procura-se analisar como fazer para aumentar o seu índice de utilização e, ao mesmo tempo, atender às exigências em termos das fontes de informação já citadas. Mesmo que tal maquinário não atenda a 100\% das exigências do projeto, ela será utilizada, pois há o objetivo de reduzir custos.

Assim, na fase de desenvolvimento, há uma grande preocupação com a eficiência dos processos, o aproveitamento de matérias-primas, de modo que se possa fabricar um produto diferenciado a um preço competitivo. A redução dos tempos envolvidos no processo, a rápida resposta às necessidades dos clientes e a diminuição dos custos, estão estreitamente relacionados com o ato de projetar para obter facilidade de produção (HANDFIELD, 1993), o qual está associado à especificação, simplificação e padronização. (GAITHER e FRAZIER; 2001)

Entretanto, uma vez que a eficiência interna deve estar associada à orientação para o mercado, é inevitável que ainda existam divergências entre a área de desenvolvimento e a área industrial, como pode ser ilustrada no depoimento da profissional responsável pelo desenvolvimento de produtos:

Existe, algumas vezes, muito atrito entre a área de desenvolvimento de produto e a área industrial no processo de criação, pois apesar de eu fazer muitas concessões de produção para otimizar o processo, existem certos detalhes artesanais que não abro mão, pois tenho convicção que se tornará uma tendência de mercado. E como um trabalho artesanal gera maior complexidade, o pessoal da área industrial algumas vezes tenta me dissuadir da idéia. Mas a mentalidade está mudando. Em 13 de junho de 2003, nós lançamos uma linha que, em termos de tabela de itens, continha 4.000 itens. Mas em termos de produção isto deu 20.000 itens. O setor industrial não gostou, mas compreendeu que havia a necessidade deste lançamento para consolidar a imagem da empresa no mercado.

De fato, a mentalidade está mudando, como pode ser constatado por meio do posicionamento do Gerente Industrial:

Inicialmente era a área industrial que ficava responsável em desenvolver o produto. Mas quando se tem só a visão industrial você começa a castrar bastante, pois se prioriza apenas a parte de otimização. Hoje existe um comitê interno para definir o produto. Então nós participamos do comitê, mas no primeiro momento é importante que a gente fique de fora, para não limitar o projeto. [...] Nós, da área de processos, 
não estamos mais tão radicais. Olhávamos muito os custos e as perdas. Atualmente, em função da mudança de nossa atuação no mercado, explorando uma faixa de consumidores classe $\mathrm{A}$ e $\mathrm{B}$, não estamos mais olhando só custo para definir a viabilidade de produção, estamos mais flexíveis. Estamos olhando o produto final.

Assim, observa-se que o foco no produto e na produção tem migrado para uma abordagem eficientemente orientada para o cliente. Esta compreensão de que um setor deve se voltar mais para o atendimento ao cliente do que para a produção de bens já havia sido contemplada por Levitt (1960) como um requisito necessário para melhorar a competitividade das empresas.

\subsubsection{Produção enxuta}

Na busca pela otimização dos recursos, alguns itens são priorizados: controle direto, envolvimento de pessoas e melhoria contínua. Esforça-se, ainda, para implementar o conceito da tecnologia limpa, evitando ao máximo a criação de resíduos.

Uma vez que o custo da matéria-prima representa 70 a $80 \%$ do custo do produto, busca-se implementar ações que concorram para a redução das perdas. Neste sentido, esforça-se para aumentar, continuamente, a eficiência do plano de corte.

Para otimizar o plano de corte, o PCP analisa as dimensões exigidas pelo cliente e identifica qual a seqüência mais apropriada de pedidos para reduzir ao máximo as perdas. As peças, ao longo do processo, são identificadas por meio de códigos de barra. Os códigos indicam as especificações individuais dos clientes. Desta forma, funcionários e máquinas irão realizar a leitura dos códigos e efetuar as operações necessárias.

Sob a perspectiva da fabricação de materiais lineares, enquanto as fábricas de móveis tradicionais trabalham peça a peça, quer dizer, no momento em que se faz o plano de corte está se cortando uma base, uma lateral, uma prateleira, o processo da empresa corta barras. Este diferencial permite que haja menos perdas e que aumente a velocidade da fabricação.

Para isto, utilizam-se chapas com o dobro das dimensões do mercado para conseguir maior aproveitamento no corte. Este é um padrão já utilizado na Europa, mas é novo no Brasil. Isto implicou que os fabricantes de chapas tivessem que se adaptar às suas necessidades.

Os lojistas também contribuem para o melhor aproveitamento da matéria prima, seguindo determinados padrões para diferenciar os produtos para os clientes finais, de modo a não aumentar a complexidade da fabricação. Profundidade de balcão e armários, por exemplo, são medidas padronizadas e que são seguidas pelos lojistas. Desta forma, torna-se mais fácil a fabricação, pois são exigidas apenas poucas modificações nos padrões.

A parceria com os fornecedores, as ações internas e o comprometimento dos lojistas contribuíram para que as perdas alcançassem um índice de apenas 5\%. A principal perda é 
decorrente do pó proveniente do corte. Em relação ao retrabalho, tem-se um índice de aproximadamente $0,8 \%$.

Ademais, caso haja problemas de qualidade e estes sejam detectados, os funcionários têm autonomia para parar o processo e só recomeçar quando achar conveniente ou por ordem superior. Para evitar erros, em alguns pontos do processo, existem dispositivos que detectam anormalidades. Por exemplo: certas máquinas são programadas para determinadas medidas. Caso haja outra medida de material que não aquele programado, a máquina irá parar automaticamente. Observam-se, pois, aspectos associados ao conceito de autonomação, o qual representa um dos pilares da produção enxuta (OHNO, 1997).

Neste contexto, Ross (1998), Mann (2000) e Silveira, Borenstein e Fogliatto (2001) destacam a importância da adoção de práticas relacionadas à produção enxuta para habilitar a empresa a implementar com sucesso a estratégia de customização em massa.

A identificação de soluções inovadoras para o aproveitamento de materiais também é estimulada e corrobora os achados de Pine (1994), como pode ser constatado na situação discriminada a seguir:

No momento em que o pesquisador visitava a área fabril da empresa, defrontou-se com um grande volume de material estocado após as máquinas seccionadoras. Ao questionar a razão de tal volume de material estocado, recebeu a explicação que estes seriam capas protetoras das chapas que são postas pelo fornecedor para não danificar o produto durante o manuseio. Ou seja, não corresponde à matéria-prima em si.

Como elas não participam do processo, vez que são retiradas logo no início das atividades pelas próprias máquinas, estocam-se as mesmas com o intuito de gerar um incômodo nos funcionários, a fim de que os mesmos se sintam desafiados a descobrirem uma serventia para o uso do material. Afinal, houve um custo para sua aquisição.

O material poderia já ter sido vendido, pois já tinha havido propostas para isto, mas os gestores acreditam que seja possível utilizá-los de alguma maneira. "É claro que não poderíamos usar nas partes nobres dos móveis, mas acreditamos que seja possível utilizar em algum ponto do processo", explica o Analista Técnico do setor produtivo.

\subsubsection{Manufatura baseada no tempo e cadeia de suprimentos}

Desde o início da década de noventa a empresa tem se esforçado para adotar uma gestão participativa e reduzir o número de níveis hierárquicos. Um importante passo em prol deste objetivo foi a implantação, em 1994, do Sistema de Excelência. Como decorrência, foram montados células de produção, com os operadores trabalhando em equipe. 
Neste contexto, uma vez por semana, as células de trabalho são paradas para que sejam feitas reuniões no intuito de discutir problemas e melhorias no processo. "Não abrimos mão da participação dos funcionários nas reuniões. [...] Diferente dos Círculos de Controle da Qualidade, não é facultativo ao operador a sua participação", afirma o Gerente Industrial.

De acordo com o Analista Técnico, têm-se vários exemplos de idéias que propiciaram melhorias nos processo, como os resultados alcançados na redução do tempo de alimentação de certas máquinas, por exemplo. Nesta linha, foi implantado um programa formal de sugestões, contendo formulários e procedimentos próprios para apresentação de sugestões de melhoria pelos funcionários. Estas melhorias são encaminhadas para concorrerem à melhor idéia do mês e as vitoriosas são remuneradas.

A participação dos empregados do chão de fábrica na resolução de problemas e o uso de manufatura celular são práticas de manufatura baseada no tempo defendidas por Tu, Vanderembse e Ragu-Nathan (2001) para a melhoria do desempenho de sistemas de customização em massa.

A velocidade do fluxo produtivo, por sua vez, é decorrente, principalmente, da fabricação e estoque de peças padronizadas intercambiáveis, no processamento de matérias lineares. São apenas três as etapas deste processo: corte, colagem de bordas e perfuração. Daí segue para o estoque intermediário (almoxarifado).

Por outro lado, devido à grande quantidade de atividades desempenhadas pelas máquinas envolvidas no processo de fabricação, as quais apresentam diferentes setups, uma das prioridades para reduzir o lead time é a redução dos tempos de preparação dos equipamentos. Atualmente, consomem-se, aproximadamente, oito horas para atravessar os insumos e transformá-los em produtos acabados.

Em relação ao fornecimento, há dois tipos de fornecedores: o primeiro tipo é o responsável pela matéria-prima a ser utilizada na fabricação dos componentes padronizados e demais peças customizáveis. Dependendo da logística e da distância do fornecedor, têm-se políticas diferentes para manutenção de estoques.

O segundo tipo de fornecedor é aquele responsável pela entrega de produtos finais, tais como portas de alumínio. Neste caso ele participa mais ativamente da criação de novos produtos. Em relação à logística, ele participa dentro de uma política sistemista (semelhante à praticada pela montadora de automóveis GM no município de Gravataí-RS), entregando no dia da embalagem, ou no box de expedição, quando se está realizando a seleção de peças componentes de uma determinada referência final.

Para trabalhar com a política sistemista, por sua vez, é necessário que os fornecedores estejam próximos à fábrica ou, pelo menos, na mesma região. "Isto é essencial para alcançar o nível de eficiência operacional. Desta maneira podemos realizar pedidos diferentes a preços 
competitivos", afirma o Gerente Industrial. A localização da fábrica do fornecedor junto ao cliente foi contemplada por Kotha (1996) como uma das condições para o sucesso da estratégia de customização em massa.

Para monitorar o desempenho dos fornecedores, existe um comitê formado por integrantes da área de suprimentos e produção que faz uma avaliação trimestral, por meio de vários indicadores, tais como qualidade, prazo de entrega etc. Dá-se nota a cada item avaliado.

Por outro lado, os lojistas também têm um papel fundamental na estratégia de customização em massa da empresa. Afinal, os clientes interagem exclusivamente com eles, seja no momento da definição do projeto, seja durante a fase compreendida entre o pedido e o recebimento do produto final. Logo, o desempenho das atividades de atendimento executadas pelo lojista corresponde a um dos principais atributos avaliados pelos clientes para alcançar satisfação no processo de compra.

$\mathrm{Na}$ fase de projeto, por exemplo, há esforços para que os lojistas atendam às necessidades dos clientes por meio dos itens componentes padronizados e catalogados no software Promob, de modo que a customização ocorra sem gerar complexidade para a área produtiva. Na fase de entrega do produto, por seu turno, o lojista realiza pré-montagens e os ajustes necessários para atender adequadamente aos requisitos especificados pelos clientes.

$\mathrm{O}$ aprofundamento das relações com o conjunto de empresas que faz parte da cadeia de suprimentos cria, entre outras, a possibilidade de implementar com sucesso certas práticas de gestão (PIRES, 1998). Uma vez que a customização em massa prevê a fabricação e entrega de produtos únicos, no menor tempo e custo possíveis, a cadeia de suprimentos assume um papel de extrema relevância para o sucesso desta estratégia (KOTHA, 1996; EASTWOOD, 1996; FEITZINGER e LEE, 1997; ZIPKIN, 2001; SILVEIRA, BORENSTEIN, FOGLIATTO, 2001; TU, VANDEREMBSE, RAGU-NATHAN, 2001; HERMANSKY, SEELMANN-EGGEBERT, 2003).

\section{Conclusões}

O objetivo deste artigo foi analisar as estratégias de customização em massa adotadas por uma empresa pertencente ao setor de fabricação de móveis modulares. Para isto, buscou-se diagnosticar o processo produtivo e as implicações da adoção destas estratégias para o gerenciamento das operações. Ademais, também foi possível identificar os habilitadores da customização em massa adotados pela empresa pesquisada. A estratégia de pesquisa selecionada foi de estudo de caso, e entrevistas semi-estruturadas foram adotadas como principal técnica para coleta de dados.

A análise dos resultados permitiu concluir que foram adotadas estratégias alicerçadas na utilização de módulos e postergação da manufatura. O uso de módulos otimiza não apenas as 
atividades de montagem, mas também favorece a disponibilização de produtos que possam ser configurados pelos próprios consumidores, de modo a atenderem suas próprias necessidades.

Nesta perspectiva, não se fabrica todas as combinações potenciais de um produto para estocar (pois, além dos custos com estoque, há tantas combinações possíveis para um dado produto que seria impossível adotar tal procedimento), no intuito de reduzir o prazo de entrega ao cliente. Espera-se receber um pedido de um dado cliente e depois se elabora o produto encomendado montando-o a partir de uma combinação de componentes. Esta abordagem, contudo, pressupõe que o número de atributos passíveis de ser customizados seja limitado ao resultado das possíveis permutações de componentes modulares projetados e os produtos aos quais serão agregados.

A postergação da manufatura, por sua vez, significa retardar certas tarefas de diferenciação envolvidas na produção até que se receba o pedido do cliente. Especificamente no caso diagnosticado, empreendeu-se a postergação da fabricação e da montagem. Por meio de um ponto de desacoplamento do pedido, o processo produtivo se divide em dois estágios: padronização e customização, onde o primeiro permite ganhos associados à economia de escala e o segundo agrega valor ao produto de acordo com as necessidades individuais do cliente.

Neste contexto, a pesquisa possibilitou identificar a existência de dois pontos distintos de desacoplamento do pedido do cliente: corte das peças dos tampos e das prateleiras lineares para assumirem comprimentos específicos (possibilitando a postergação da fabricação), e montagem e ajuste dos módulos na residência do cliente (possibilitando a postergação da montagem). Percebese, pois, a relação existente entre postergação e modularidade em prol da customização em massa.

Seis habilitadores foram considerados essenciais para os propósitos da customização em massa: tecnologia de informação (TI), flexibilidade do sistema produtivo, projeto do produto, produção enxuta, manufatura baseada no tempo e cadeia de suprimentos. A TI contribui não apenas para permitir a interação com os clientes e a emissão do pedidos nas lojas exclusivas da empresa, por meio do acesso aos componentes padronizados disponíveis para a elaboração do projeto do móvel desejado, mas também para melhorar o desempenho da área produtiva.

Neste último caso, por meio do uso de automação e sistemas de informação, eleva-se a flexibilidade e a velocidade do sistema de manufatura, reduzem-se custos unitários e problemas associados às falhas da qualidade do produto, além de prover o suporte para as tarefas de planejamento e controle de materiais. A flexibilidade, por sua vez, corresponde a um importante fator em prol da customização em massa, na medida em que contribui para lidar com as variabilidades de saída e incertezas ambientais. Neste sentido, os principais tipos de flexibilidade demandados foram os seguintes: máquina, mão de obra, modificação do produto, mix e volume.

Em termos do projeto do produto, há um forte empenho para que a concepção de novas peças obedeça à modularização pré-existente na linha de produção, de modo a não comprometer a 
eficiência dos processos. Todavia, destacam-se os esforços para conciliar esta abordagem com uma orientação para o mercado. O alinhamento entre a área industrial e a de desenvolvimento de produto tem contribuído sobremaneira para alcançar este propósito.

Práticas relacionadas à produção enxuta e manufatura baseada no tempo também foram identificadas, tais como: multifuncionalidade, autonomação, redução de setups, operações padronizadas, manufatura celular, participação dos empregados na resolução de problemas e esforços para a melhoria da qualidade.

Por fim, o estreito relacionamento com os fornecedores e os lojistas mostrou-se fundamental para atingir o desempenho planejado. Afinal, para garantir a satisfação dos clientes em relação às suas necessidades individuais, não é possível apenas assegurar que a empresa será eficiente em seus processos internos. Mais do que o alcance desse objetivo é necessário maximizar potenciais sinergias entre os elos da cadeia de suprimentos, de forma a reduzir custos, prazos e agregar mais valor aos produtos finais.

\begin{abstract}
This paper aims at analyzing the mass customization strategies adopted by a leader company of the modulated furniture manufacture segment. The research strategy chosen was the single case study. In order to obtain the necessary data, semi-structured interviews were used. The analysis of the data was accomplished in five phases. The results allowed verifying that modularity-based manufacturing strategies, manufacturing postponement and assembly postponement were adopted. The existence of two customer order decoupling point was identified. Six enablers were considered essential for mass customization: time-based manufacturing, supply chain, production system flexibility, product project, lean manufacturing and information technology.
\end{abstract}

Key-words: Mass customization, strategy, case study, modularization, postponement.

\title{
Referências
}

BERMAN, B. Should your firm adopt a mass customization strategy? Business Horizons, p.51-60, jul.-aug. 2002.

BOWERSOX, D. J.; CLOSS, D. J. Logística empresarial: o processo de integração da cadeia de suprimento. São Paulo: Atlas, 2001.

CARMO, F. D. C. F.; GAVRONSKI, I. Jit aproach to mass customization: a case study. In: ENCONTRO DA ASSOCIAÇÃO DOS PROGRAMAS DE PÓS-GRADUAÇÃO EM ADMINISTRAÇÃO, 26., 2002, Salvador. Anais... Bahia: ANPAD, 2002. 1CD.

COLLIS, J. HUSSEY, R. Pesquisa em administração: um guia prático para alunos de graduação e pós-graduação. 2.ed. Porto Alegre: Bookman, 2005.

DORNIER, P. e outros. Logística e operações globais: texto e casos. São Paulo: Atlas, 2000.

DURAY, R. e outros. Approaches to mass customization: configurations and empirical validation. Journal of Operations Management, v.18, p.605-625, 2000.

cross ${ }^{\text {ref }}$

EASTWOOD, M. A. Implementing mass customization. Computers in Industry, v.30, n.3, p.171-174, 1996. cross' 
FEITZINGER, E.; LEE, H. Mass customization at Hewlett-Packard: the power of postponement. Harvard Business Review, p.116-121, jan/feb. 1997.

GAITHER, N.; FRAZIER, G. Administração da produção e operações. 8.ed. São Paulo: Pioneira Thomson Learning, 2001.

GHINATO, P. Autonomia e multifuncionalidade no trabalho: elementos fundamentais na busca pela competitividade. In: GUIMARÃES, L. B. M. (ed.). Série Monográfica Ergonomia: ergonomia de processo. 2. ed. Porto Alegre: PPGEP/UFRGS, 1999, cap. 4.1, v.2.

HANDFIELD, R. B. The role of materials management in developing time-based competition. Journal of Supply Chain Management, v.29, n.1, p. 2-10, winter, 1993.

HERMANSKY, J.; SEELMANN-EGGEBERT, R. Manufacturing postponed. IEE Manufacturing Engineer, p.38-41, aug./sep. 2003.

KOTHA, S. From mass production to mass customization: the case of the National Industry Bicycle Company of Japan. European Management Journal, v.14, n.5, p. 442-450, 1996.

cross ref

LAMPEL, J.; MINTZBERG, H. Customizing Customization. Sloan Management Review, v.38, n.1, p.21-29, fall, 1996.

LAU, Ronald S. M. Mass customization: the next industrial revolution. Industrial Management, v.37, n.5, p.18-19, sep/oct, 1995.

LEE, S.; CHEN, J. C. Mass customization: methodology for an apparel industry with a future. Journal of Industrial Technology, v.16, n.1, nov./jan. 2000.

LEVITT, T. Marketing Myopia. Harvard Business Review, v.38, n.4, p.45-56, jul,/aug. 1960.

MACHADO, A. G. C. ; MORAES, W. F. A . Estratégias de customização em massa: evidências e análises em empresas do setor de confecção de artigos de vestuário. Base, v. 5, p. 17-31, 2008a.

MACHADO, A. G. C. ; MORAES, W. F. A . Estratégias de Customização em Massa implementadas por empresas brasileiras. Produção, v. 18, n. 1, p. 170-183, jan./abr. 2008 b.

cross ${ }^{\text {ref }}$

MACHADO, A. G. C.; MORAES, W. F. A. Da produção em massa à customização em massa: sustentando a liderança na fabricação de motores elétricos. Cadernos EBAPE. BR, v. 7, n. 4, dez. 2009.

MANN, P. Mass customization simplified. Manufacturing Systems, v.18, Iss. 9, p.16, sep. 2000.

MERRIAM, S. B. Qualitative research and case study applications in education. Jossey-Bass: San Francisco, 1998.

OHNO, T. Sistema Toyota de Produção - além da produção em larga escala. Porto Alegre: Artes Médicas, 1997.

PAGH, J. D.; COOPER, M. C. Supply chain postponement and speculation strategies: how to choose the right strategy. Journal of Business Logistics, v.19, n.2, p. 13-33, 1998.

PEPPERS, Don; ROGERS, Martha. Empresa 1:1: instrumentos para competir na era da interatividade. Rio de Janeiro: Campus, 1997.

PILLER, F. T. Observations on the present and future of mass customization. International Journal of Flexible Manufacturing System, v.19, p.630-636, 2007.

cross ${ }^{\text {ref }}$

PINE, B. J. Personalizando produtos e serviços - customização maciça. São Paulo: Makron Books, 1994. 
PIRES, Silvio R. I. Gestão da cadeia de suprimentos e o modelo de consórcio modular. Revista de Administração, São Paulo, v.33, n.3, p.5-15, jul./set. 1998.

ROSS, A. Mass customisation: the dirty reality. IEE Manufacturing Engineer, p.79-80, apr. 1998.

SILVEIRA, G. da; BORENSTEIN, D.; FOGLIATTO, F. S. Mass customization: literature review and research direction. International Journal of Production Economics, v.72, p. 1-13, 2001.

crossef

TU, Qiang; VANDEREMBSE, Mark A; RAGU-NATHAN, T. S. The impact of time-based manufacturing practices on mass customization and value to customer. Journal of Operations Management, v.19, p.201-217, 2001.

cross ref

TU, Qiang. et al. Measuring modularity-based manufacturing practices and their impact on mass customization capability: a customer-driven perspective. Decision Sciences, v.35, n.2, p.147-168, 2004

TUBINO, Dalvio Ferrari. Sistemas de produção: a produtividade no chão de fábrica. Porto Alegre: Bookman, 1999.

VAN HOEK, R. I. The rediscovery of postponement a literature review and directions for research. Journal of Operations Management, v.19, p.161-184, 2001.

cross ref

VAN HOEK, R. I.; COMMANDEUR, H. R.; VOS, B. Reconfiguring logistics systems through postponement strategies. Journal of Business Logistics, v.19, n.1, p.33-54, 1998.

WALlER, M. A.; DABHOLKAR, P. A.; GENTRY, J. J. Postponement, product customization, and market-oriented supply chain management. Journal of Business Logistics, v.21, n.2, p.133-156, 2000.

YIN, Robert K. Estudos de caso: planejamento e métodos. 2. ed. Porto alegre: Bookman, 2001.

YANG, B.; BURNS, N. D.; BACKHOUSE, C. J. Postponement: a review and an integrated framework. International Journal Operations and Production Management, v.24, n.5, p.468-487, 2004.

cross'ref

ZINN, W. O retardamento da montagem final de produtos como estratégia de marketing e distribuição. Revista de Administração de Empresas, v.30, n.4, p.53-59, out./dez. 1990.

\section{Dados dos Autores:}

\section{Nome completo: André Gustavo Carvalho Machado}

Filiação institucional: Universidade Federal da Paraíba

Departamento: Administração

Função ou cargo ocupado: Professor Adjunto

Endereço completo para correspondência (bairro, cidade, estado, país e CEP): Rua Ovídio

Mendonça, 50/201, Miramar, João Pessoa, Paraíba, Brasil, CEP 58043-210

Telefones para contato: (83) 88138000

e-mail:agcmachado@gmail.com

\section{Nome Completo: Walter Fernando Araújo de Moraes}

Filiação Institucional: Universidade Federal de Pernambuco 
Departamento: Administração

Função Ou Cargo Ocupado: Professor Titular

Endereço Completo Para Correspondência (Bairro, Cidade, Estado, País E CEP): Rua Moraes Rêgo,

1235, Cidade Universitária, Recife, Pernambuco, Brasil, CEP: 50670901

Telefones para contato: (81) 21267165

e-mail:wfam@br.inter.net 